\title{
Enteric pathogens in pediatric patients- A Three Year Study from a tertiary care Hospital of North India
}

\author{
B. Uppal, M. Matlani \\ Department of Microbiology, \\ Dayanand Medical College \& Hospital, Ludhiana, India
}

\begin{abstract}
Acute diarrhea is a common problem in children in developing countries like India leading to hospitalization. The objective of the study was to assess the etiological agents causing diarrhea in children and their sensitivity patterns to various antimicrobials. This study was carried out from January 2007- December 2009 on 860 pediatric patients attending the out patients department or admitted in the wards of Lok Nayak Hospital, New Delhi with gastroenteritis. Eight hundred and sixty stool samples were collected and examined for various pathogens.

Enteric pathogens were isolated from 321 (37.2\%) samples. Parasitic pathogens were observed in 67 (7.79\%) stool samples. V.cholerae was the most commonly isolated bacteria 134/321 (41.74\%), followed by Shigella 90/321 (28.03\%) and E.coli 86 (27.79\%). Salmonella spp. (1.5\%) and Aeromonas hydrophila (1.86\%) were isolated less frequently. Resistance to amoxycillin was observed in $99 \%$ of Vibrio, $95 \%$ of E. coli, $58 \%$ of Shigella and $20 \%$ of Salmonella species. Variable degree of resistance ranging from 0\% in Salmonella to 69\% in E. coli was observed against ciprofloxacin, while resistance to nalidixic acid was observed in more than $90 \%$ of all types of bacterial pathogens. Resistance to ceftriaxone, cefotaxime and gentamicin was less common. Identification of the etiological agent of diarrhea in children is very important as it can help in the institution of appropriate therapy and the reduction of morbidity and mortality in these patients.
\end{abstract}

Keywords : Salmonella, V.cholerae, paediatric.

\section{INTRODUCTION}

Diarrheal diseases are a leading cause of morbidity and mortality in children in developing countries like India. More than 4 million children under 1 year of age die each year of infectious diarrhea, worldwide. ${ }^{1}$ In India, one third of the total pediatric admissions in hospitals are due to diarrheal diseases and $17 \%$ of all deaths in indoor pediatric patients are diarrhea related. ${ }^{1,2}$ Although fluid and electrolyte replacement is recommended for management of acute diarrhea, but antibacterial agents are often administered for treatment of Salmonella gastroenteritis and Shigellosis in children or even diarrhea due to E. coli or Vibrio cholerae. In India, most diarrhea infected patients are often treated with antibiotics prior to receiving

\section{Corresponding Author :}

Dr Monika Matlani

Deptt. Of Microbiology

Maulana Azad Medical College,

New Delhi, India

E-mail : monikamatlani@yahoo.com definitive laboratory results. Indiscriminate use of these agents has resulted in the development of multidrug resistant organisms. The progressive increase in antimicrobial resistance among enteric pathogens in developing countries has become a major issue of concern. ${ }^{3,4}$ Therefore, knowledge of the pattern of the infections and antibiotic susceptibility patterns of the etiological agents can often guide therapy when resource limitations hamper the exact diagnosis of diarrheas in pediatric patients. In the present study, we determined the prevalence of bacterial and parasitic pathogens in children less than 12 years of age and the antimicrobial susceptibility of important bacterial isolates over a period of three years (January 2007 to December 2009).

\section{MATERIAL AND METHODS}

An episode of acute diarrhea was defined as the passing of at least four loose stools in a 24 hours period for infants $<1$ month old and at least 3 times in a 24 hour period for older infants. Dysentery was defined as a diarrhea lasting longer than 10 days with significant fever or systemic complaints and has inflammatory cells or blood in the stool. ${ }^{1,5}$ 
Stool samples were collected from 860 infants and children (less than 12 years) with acute diarrhea presenting to the outpatient department or admitted in the ward of Lok Nayak hospital, during January 2007 to December 2009. Single stool sample was taken from each patient. Routine stool microscopy of saline and iodine preparations was done for intestinal parasites following the standard formol ether method of concentration. A battery of culture media- alkaline peptone water, selenite F broth, Mac Conkey's agar, bile salt agar (BSA), xylose lysine deoxycholate (XLD), were used for isolation of bacterial pathogens. All the isolates were subjected to standard biochemical tests for identification. Salmonella, Shigella, E. coli, and V. cholerae isolates were serotyped by slide agglutination test using commercially available specific antisera (Denka Seiken Co. Ltd.). Antimicrobial susceptibility testing was performed on Mueller Hinton Agar (MHA) by Kirby Bauer's disc diffusion method. ${ }^{6}$ The following standard antimicrobial discs were tested: amoxycillin $(30 \mu \mathrm{g})$, gentamicin $(10 \mu \mathrm{g})$, ciprofloxacin $(5$ $\mu \mathrm{g})$, ceftriaxone $(30 \mu \mathrm{g})$, cefotaxime $(30 \mu \mathrm{g})$, nalidixic acid $(30 \mu \mathrm{g})$ and tetracycline $(30 \mu \mathrm{g})$.

\section{RESULTS}

Amongst the 860 children (1-12 years), 434 (50.46\%) were of less than 2 years of age. The youngest was three months and the oldest was eleven years. The mean age of the diarrheal cases was 17.1 months. Out of 860 fecal specimens, 321 (37.2\%) isolates were obtained. Amongst the 860 specimen, parasitic pathogens were observed in 67 stool samples. Giardia lamblia was the most frequently 21/67 (31.34\%) observed non-bacterial enteric pathogen. Ascaris lumbricoides was found in
19/67 (28.35\%) samples, Ancylostoma duodenale in 16/ 67 (23.8\%) and H. nana was found in 7 of 67 diarrheal stools positive for parasites (Table I). Cryptosporidium was found in 4/67(5.9\%) parasite positive diarrheal stools. However, HIV status of these 4 patients could not be evaluated due to loss of follow up.

The most frequently isolated bacterial agent was $V$. cholerae 134/321(41.74\%). V. cholerae O1 El Tor 126/ $134(94.02 \%)$ was more common than V. cholerae $\mathrm{O} 139$ $1 / 134(0.74 \%)$. However, 7/134(5.22\%) isolates were found to be non $\mathrm{O} 1$ nonO139 serotypes. Serotype Ogawa $106 / 126(84.12 \%)$ was more predominant than serotype Inaba 20/126 (15.87\%). Shigella was isolated in 90/321 (28.03\%) samples obtained from cases with dysentery. Amongst the Shigella species isolated, Shigella flexneri was most common $(n=66 / 90,73.3 \%)$ isolate, followed by Shigella dysenteriae $(\mathrm{n}=14 / 90,15.5 \%)$, Shigella boydii $(\mathrm{n}=8 / 90,8.8 \%)$, and Shigella sonnei $(\mathrm{n}=2 / 90$, $2.2 \%)$. All the E.coli isolates 86 (26.79\%), seen as pure growth and abundant colonies were subjected to the serotyping. EPEC was most common, accounting for 45/ $86(52.3 \%)$ of the E.coli isolated from diarrheal stools. While, enterotoxigenic, enterohemorrhagic, enteroinvasive E. coli were isolated in 20 (23.2\%),14 (16.27\%), and 7 $(8.13 \%)$ cases respectively. Salmonella was isolated from $5(1.5 \%)$ samples (4 Salmonella Typhimurium and one Salmonella Typhi), while Aeromonas was isolated from $6(1.86 \%)$ samples (Table I).

The resistance pattern of these isolates is shown in table II. V.cholerae isolates showed more than $91 \%$ resistance to amoxycillin and nalidixic acid. However

Table I

Year wise distribution of enteropathogens isolated/ observed

\begin{tabular}{lccccc}
\hline Bacterial Pathogens & $\mathbf{2 0 0 7}$ & $\mathbf{2 0 0 8}$ & $\mathbf{2 0 0 9}$ & Total & Cumulative total \\
\hline Vibrio & 55 & 27 & 52 & $134(41.74 \%)$ & 134 \\
Shigella & 30 & 22 & 38 & $90(28.03)$ & 224 \\
E. coli & 25 & 28 & 33 & $86(27.79)$ & 310 \\
Salmonella & 3 & 1 & 1 & $5(1.55)$ & 315 \\
Aeromonas & 2 & 3 & 1 & $6(1.86)$ & 321 \\
Parasitic Pathogens & & & & & \\
Ascaris & 8 & 6 & 5 & $19(28.3)$ & 19 \\
Giardia & 5 & 7 & 9 & $21(31.3)$ & 40 \\
H. nana & 3 & 2 & 2 & $7(10.4)$ & 47 \\
Hookworm & 4 & 5 & 7 & $16(23.8)$ & 63 \\
Cryptosporidia & 0 & 3 & 1 & $4(6)$ & 67 \\
\hline
\end{tabular}


Table II

Resistance patterns observed in bacterial pathogens

\begin{tabular}{llllllll}
\hline Organism & $\begin{array}{l}\text { Cipro- } \\
\text { floxacin }\end{array}$ & $\begin{array}{l}\text { Nalidixic } \\
\text { Acid }\end{array}$ & $\begin{array}{l}\text { Amoxy- } \\
\text { cillin }\end{array}$ & $\begin{array}{l}\text { Cefo- } \\
\text { taxime }\end{array}$ & $\begin{array}{l}\text { Ceftria- } \\
\text { xone }\end{array}$ & $\begin{array}{l}\text { Genta- } \\
\text { micin }\end{array}$ & $\begin{array}{c}\text { Tetra- } \\
\text { cycline }\end{array}$ \\
\hline Vibrio & $5 \%$ & $91.7 \%$ & $99 \%$ & $3.8 \%$ & $0.5 \%$ & $2 \%$ & $9 \%$ \\
Shigella & $4.7 \%$ & $97 \%$ & $58 \%$ & $3 \%$ & $2 \%$ & $4 \%$ & - \\
E. coli & $69 \%$ & $91 \%$ & $95 \%$ & $5 \%$ & $0 \%$ & $11 \%$ & - \\
Salmonella & $0 \%$ & $20 \%$ & $20 \%$ & $20 \%$ & $20 \%$ & $20 \%$ & - \\
Aeromonas & $19 \%$ & $95 \%$ & $97 \%$ & $6 \%$ & $5 \%$ & $15 \%$ & - \\
\hline
\end{tabular}

resistance to ceftriaxone, ciprofloxacin, gentamicin, cefotaxime, and tetracycline varied from $0.5 \%$ to $9 \%$. The isolated strains of Shigella were highly resistant (97\%) to nalidixic acid, while resistance to amoxicillin was demonstrated by $58 \%$ strains. The percentage resistance shown against gentamicin, ciprofloxacin ceftriaxone and cefotaxime, was 4\%, 4.7\%, $2 \%$ and $3 \%$ respectively. Amongst 5 salmonella isolates (4 Salmonella Typhimurium and one $S$. Typhi), only one ( $S$. Typhimurium) showed multidrug resistance. This strain was resistant to amoxycillin, gentamicin, ceftriaxone, cefotaxime, and nalidixic acid, while sensitive to ciprofloxacin. Rest four isolates were all sensitive to all antibiotics. The resistance pattern of Aeromonas revealed 5-19\% resistance to ciprofloxacin, gentamicin, ceftriaxone and cefotaxime, whereas resistance to amoxicillin and nalidixic acid was $95 \%$ and $97 \%$ respectively.

\section{DISCUSSION}

Our hospital is a 1690 bedded tertiary care hospital with thickly populated catchment areas and most of the patients fall in the low and middle socio economic status. This could have led to higher isolation rate of bacteria and parasites in this study (40.4\%) as compared to another study from Delhi. ${ }^{1}$ In agreement with other reports, Shigella and E. coli were the most common isolates in children. ${ }^{7,8}$ The prevailing serotype of $E$. coli leading to childhood diarrhea in our population was EPEC serotype $\mathrm{O} 111(10.5 \%)$ and serotypes $\mathrm{O} 119(8 \%)$. The association between EPEC and infantile diarrhea has already been established ${ }^{9}$ and our findings reconfirm this fact. In various studies, the susceptibility pattern of diarrhoea-causing bacteria, including Shigella, E. coli, Vibrio cholerae and Salmonella to gentamicin, nalidixic acid and norfloxacin was found to be low while resistance to ampicillin and tetracycline was found to be more than $50 \% .^{10,11}$ In our study, we also noted very high degree of resistance to amoxycillin and nalidixic acid. However resistance to gentamicin, amikacin and third generation cephalosporins was low. Hence it is required to keep these drugs in reserve and to minimize their overuse to prevent development of resistance to theses therapeutic agents.

Besides the well-known causes of enteric infections and diarrheal diseases, parasites and viruses are important etiological agents, which are often overlooked. On stool examination for ova and cyst. Ascaris was found in $28.35 \%(19 / 67)$, G. lamblia in $31.34 \%$ (21/67), A. duodenale in $23.8 \%$ (16/67), and H. nana in $10.4 \%$ (7/ 67 ) of the cases. Cryptosporidia were found in only four cases. These findings correlate with the findings from other workers in India. ${ }^{12}$ It is important to rule out parasitic causes, since unnecessary treatment of such cases with empirical antibiotics will needlessly increase the burden of drug resistance. ${ }^{1}$ Although bacterial agents are important causes of diarrhea in children but still indiscriminate use of potent antibiotics should be avoided as it can lead to acquisition of multiple drug resistance. Increasing antibiotic resistance in bacterial pathogens is now a common phenomenon in developing countries, including India. This is attributed to the injudicious use of antibiotics and frequent use of over-the-counter drugs without proper medical supervision. ${ }^{1,3}$ Recently few studies have reported the circulation of highly resistant

-lactamase-producing bacteria in public water supplies and sewage water samples in New Delhi, which is a major health concern. ${ }^{13}$ This again may be related to imprudent overuse of antibiotics in our set up. Hence 
regular monitoring of antimicrobial resistance profiles should be done and an antibiotic policy should be formulated in every hospital, to prevent development and spread of highly resistant strains.

\section{REFERENCES}

1. Das S, Saha R, Singhal S. Enteric pathogens in north Indian patients with diarrhea. Indian J Community Med 2007;32: 27-31.

2. Park K. Acute diarrhea diseases. In: Park K, editor. Parks textbook of preventive and social medicine. 18th ed. Jabalpur: Banarasidas Bhanot; 2005. p. 171-4.

3. Tjaniadi P, Lesmana P, Subekti D, Machpud N, Komalarini S, Santoso W et al. Antimicrobial resistance of bacterial pathogens associated with diarrheal patients in Indonesia. Am J Trop Med Hyg 2003;68(6):666-70.

4. Kosek M, Yori PP, Pan WK, Olortegui MP, Gilman RH, Perez $\mathrm{P}$ et al. Epidemiology of highly endemic multiply antibioticresistant shigellosis in children in the Peruvian Amazon. Pediatrics 2008;122:541-9.

5. Tintinalli JE, Kalen GD, Stapczyunski. Textbook of Emergency Medicine-a comprehensive study guide. 6th ed. Mc Graw Hill, Medical Publishing Div; 2004. p.812.

6. Bauer AW, Kirby WM, Sherris JC, Turck M. Antibiotic susceptibility testing by a standardized single disk method. Am J Clin Pathol 1966;45(4):493-6.

7. Taneja N, Mohan B, Khurana S, Sharma M. Antimicrobial resistance in selected bacterial enteropathogens in North India.
Indian J Med Res 2004;120:39-43.

8. Albert M, Faruque SM, Faraque ASG, Neogi PKB, Asarcizzamin M, Bhuiiyan NA et al. Controlled study of Escherichia coli diarrheal infections in Bangladeshi children. J Clin Microbiol 1995;33:973-7.

9. Addy PAK, Antepim G, Frimpong EH. Prevalence of pathogenic Escherichia coli and parasites in infants with diarrhoea in Kumasi, Ghana. East Afr Med J 2004;81:353-7.

10. Samie A, Guerrant RL, Barrett L, Bessong PO, Igumbor EO, Obi CL. Prevalence of intestinal parasitic and bacterial pathogens in diarrheal and non-diarrheal human stools from Vhembe district, South Africa. J Health Popul Nutr 2009;27(6):739-45.

11. Samal SK, Khuntia HK, Nanda PK, Satapathy CS, Nayak SR, Sarangi AK et al. Incidence of bacterial enteropathogens among hospitalised diarrheal patients from Orissa, India. Jpn J Infect Dis 2008;61:350-5.

12. Ayyagari A, Sharma AK, Prasad KN, Dhole TN, Kishore J, Chaudhary G. Spectrum of opportunistic infections in human immunodeficiency virus (HIV) infected cases in a tertiary care hospital. Indian J Med Microbiol 1999;17:78-80.

13. Walash RT, Weeks J, Livermore DM, Toleman MA. Dissemination of NDM-1 positive bacteria in the New Delhi environment and its implications for human health; an environmental point prevalence study. Lancet Infect Dis 2011;11:355-62. 


\section{PDF created with pdfFactory Pro trial version www.pdffactory.com}

